\title{
QUANTIDADE DE ÁGUA TRANSPIRADA PELO CAFEEIRO SOMBREADO E PELO INGÄZEIRO
}

Coaract M. Franco e Romed Inforzato, engenheiros agrônomos, Secção de Fisiologia $e$ Alimentação das Plantas, Instituto Agronômico de Campinas

\section{1 - INTRODUÇÃO}

Em trabalhos anteriores $(\mathbf{1}, \mathbf{2}, \mathbf{5})$, mostrou-se que a árvore de sombra faz séria concorrência ao cafeeiro na absorção da água do solo, nas épocas sêcas. Êste deve mesmo ser o fator principal pelo qual a prática do sombreamento não se difundiu em nosso Estado.

$O$ conhecimento da quantidade de água transpirada pelo cafeeiro sombreado e pela árvore de sombra não sòmente iria trazer novas luzes sôbre aquêle problema, como forneceria também dados bastante úteis para estudos de irrigação de cafèzais sombreados. Por êsse motivo, uma série de medições foi realizada sôbre a transpiração do ingàzeiro (Inga edulis Mart.) calculando-se também a quantidade de água retirada do solo pelos cafeeiros quando se acham sombreados por aquelas plantas. Deve-se ter em mente que trabalhos desta natureza não podem ser executados com grande exatidão. Por um lado, as dificuldades práticas encontradas impedem a obtenção de dados em número suficiente para se poder efetuar sua análise estatística. Por outro lado, os fatôres que influem na quantidade de água transpirada, anualmente, por uma planta, em condições de cultura, são tantos e tão diversos, e as precipitações pluviométricas tão variáveis de ano para ano, que tornariam sem expressão prática os resultados de uma análise estatística rigorosa obtida com dados de um determinado ano.

Assim sendo, os resultados apresentados deverão ser tomados como indicadores apenas da ordem de grandeza dos fenômenos estudados e não como uma medida exata dêsses fenômenos.

\section{2 - MATERIAL E MÉTODO}

Empregou-se, neste trabalho, a espécie Inga edulis, por ser a mais geralmente aconselhada para árvore de sombra do cafeeiro em nosso Estado. Os métodos empregados para a determinação da transpiração, superfície foliar das plantas em estudo, contrôle da umidade do solo nos vasos, etc., foram em tudo idênticos aos já descritos em trabalho recentemente publicado (4). Por essa razão achou-se desnecessário dar novamente a sua descrição. Aliás, os estudos da transpiração do ingàzeiro e do cafeeiro foram feitos simultâneamente. Empregou-se apenas um ingàzeiro em cada mês, ao invés de três, como no caso dos cafeeiros, e isto devido à 
falta não só de espaço nos vagonetes da casa de vegetação como de vasos grandes, especiais, de chapa.

\section{3 - SUPERFÍCIE FOLIAR DO INGAZEIRO}

A determinação da superfície foliar do ingàzeiro foi feita pelo mesmo método empregado no caso do cafeeiro (4). Utilizou-se uma experiência de sombreamento existente na Estação Experimental Federal de Botucatu, em virtude de aí existirem ingàzeiros com mais de 10 anos de idade, sombreando cafèzal. Escolheram-se três plantas que nos pareceram boas, não sòmente quanto à sombra produzida, como também em relação à altura da copa e número de galhos. A superfície foliar encontrada nessas três plantas estudadas foi, respectivamente, de 203,98, 215,77 e 170,75 metros quadrados, o que dá média de 196,83 metros quadrados.

Seria melhor que se determinasse a superfície foliar de um número maior de árvores, o que, entretanto, não foi possível, em vista do trabalho que isso representava e do prejuízo que cansaria à cultura.

\section{4 - RESULTADOS}

A relação seguinte mostra a transpiração do ingàzeiro, em gramas por decímetro quadrado de superfície foliar e em litros por planta, em cada mês do ano, e os totais anuais.

Transpiraģão

MÊS

$g / d m^{2}$ de fôlha

litros por planto

Janeiro

234

4615

Fevereiro

229

4505

Març

292

5755

Abril

248

4890

Maio

330

6501

Junho

281

Julh?

328

Agôsto

412

5531

Setembro

325

6452

Outubro

328

8111

Novembro

336

6397

Dezembro

270

6453

6612

3613

5318

Total anual

71140

Vê-se que o ingàzeiro transpirou durante o ano 3613 gramas de água através de cada decímetro quadrado de fôlha, o que resulta em uma transpiração total de 71140 litros, por planta, anualmente.

A transpiração diária, média, encontrada para o ingàzeiro, foi de 9,90 gramas por dia e por decímetro quadrado de superfície foliar. No dia de mais intensa transpiração, o ingàzeiro transpirou 26,397 gramas por decímetro quadrado de superfície foliar.

Como a transpiração noturna é desprezível, comparada com a grande quantidade de água transpirada durante as horas de sol, pode-se, sem 
incorrer em grande êrro, considerar o dia de 12 horas para calcular, aproximadamente, a razão da transpiração nas horas de luz. Assim fazendo, encontrou-se que a máxima razão diária de transpiração foi de 36,7 miligramas por decímetro quadrado, por minuto, bastante superior, portanto, à do cafeeiro, que foi de $17,6 \mathrm{mg} / \mathrm{dm}^{2} / \mathrm{m}(4)$.

Em trabalho anterior (3), no qual foi estudada a transpiração do cafeeiro por unidade de superfície, sob diversas intensidades luminosas, verificou-se que a transpiração das plantas submetidas a $55 \%$ da luz solar foi de $20 \%$ menos intensa do que a transpiração de outros cafeeiros, submetidos à plena luz solar. Multiplicando-se, pois, os dados referentes à transpiração do cafeeiro ao sol (4) por 0,80, encontra-se a quantidade de água transpirada pelo cafeeiro submetido a $55 \%$ de luz solar, sob condições ótimas de água no solo, ou seja a quantidade de água que o cafeeiro sombreado necessita para a sua transpiração, a fim de que não sofra as consequências da falta de água.

No quadro 1 apresenta-se a quantidade de água retirada do solo, pela transpiração do cafeeiro sombreado e pela do ingàzeiro, calculada como altura pluviométrica, ao lado das normais pluviométricas de Campinas. Para êsse cálculo, considerou-se o cafeeiro plantado no espaçamento de 3,5 × 3,5 metros e o ingàzeiro na distância de 10,5 x 10,5 metros, que são os espaçamentos que existem nas lavouras do Estado.

\section{5 - DISCUSSÃO E CONCLUSÕES}

No quadro 1 e na figura 1 vê-se que a queda pluviométrica média dos meses de maio, junho, julho e agôsto, não é suficiente nem mesmo para a transpiração do ingàzeiro plantado no espaçamento de $10,5 \times 10, \bar{\imath}$ metros.

QUADRo 1.-Transpiração do cafeeiro sombreado e do ingàzeiro, e normais pluviumétricas nos diversos meses do ano

\begin{tabular}{|c|c|c|c|c|}
\hline \multirow{2}{*}{ M E S } & \multicolumn{3}{|c|}{ Quantidade de água transpirada } & \multirow{2}{*}{$\begin{array}{l}\text { Normal pluvio- } \\
\text { métrica de } \\
\text { Campinas (em } \\
60 \text { anos) }\end{array}$} \\
\hline & $\begin{array}{l}\text { Cafeeiro som- } \\
\text { breado (1) }\end{array}$ & Ingàzeiro (2) & Total & \\
\hline & $m m$ & $m m$ & $m m$ & $m m$ \\
\hline 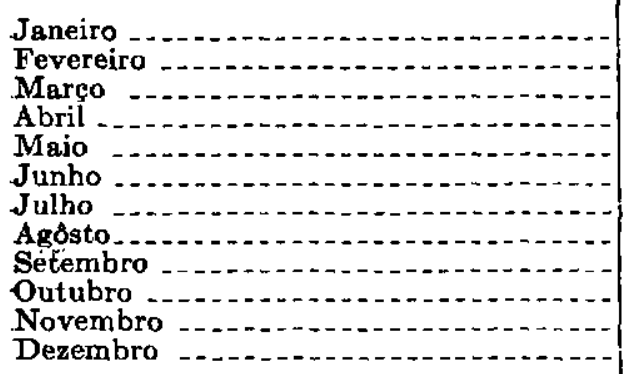 & $\begin{array}{l}40,0 \\
32,8 \\
40,8 \\
40,0 \\
42,4 \\
28,8 \\
31,2 \\
38,8 \\
44,8 \\
44,8 \\
50,4 \\
41,6\end{array}$ & $\begin{array}{l}41,8 \\
40,9 \\
52,2 \\
44,4 \\
57,4 \\
49,3 \\
59,7 \\
73,6 \\
58,0 \\
58,5 \\
60,0 \\
48,2\end{array}$ & $\begin{array}{r}81,8 \\
73,7 \\
93,0 \\
84,4 \\
99,8 \\
78,1 \\
90,9 \\
112,4 \\
102,8 \\
103,3 \\
110,4 \\
89,8\end{array}$ & $\begin{array}{r}244,6 \\
203,9 \\
149,3 \\
60,4 \\
50,7 \\
48,9 \\
28,0 \\
34,3 \\
71,3 \\
116,1 \\
155,6 \\
228,2\end{array}$ \\
\hline Total & 476.4 & 644,0 & 1120,4 & 1391,3 \\
\hline
\end{tabular}

(1) Considerando-se o espaçamento de $3.5 \times 3,5$ metros.

(2) Considerando-se o espaçamento de $10,5 \times 10,5$ metros. 


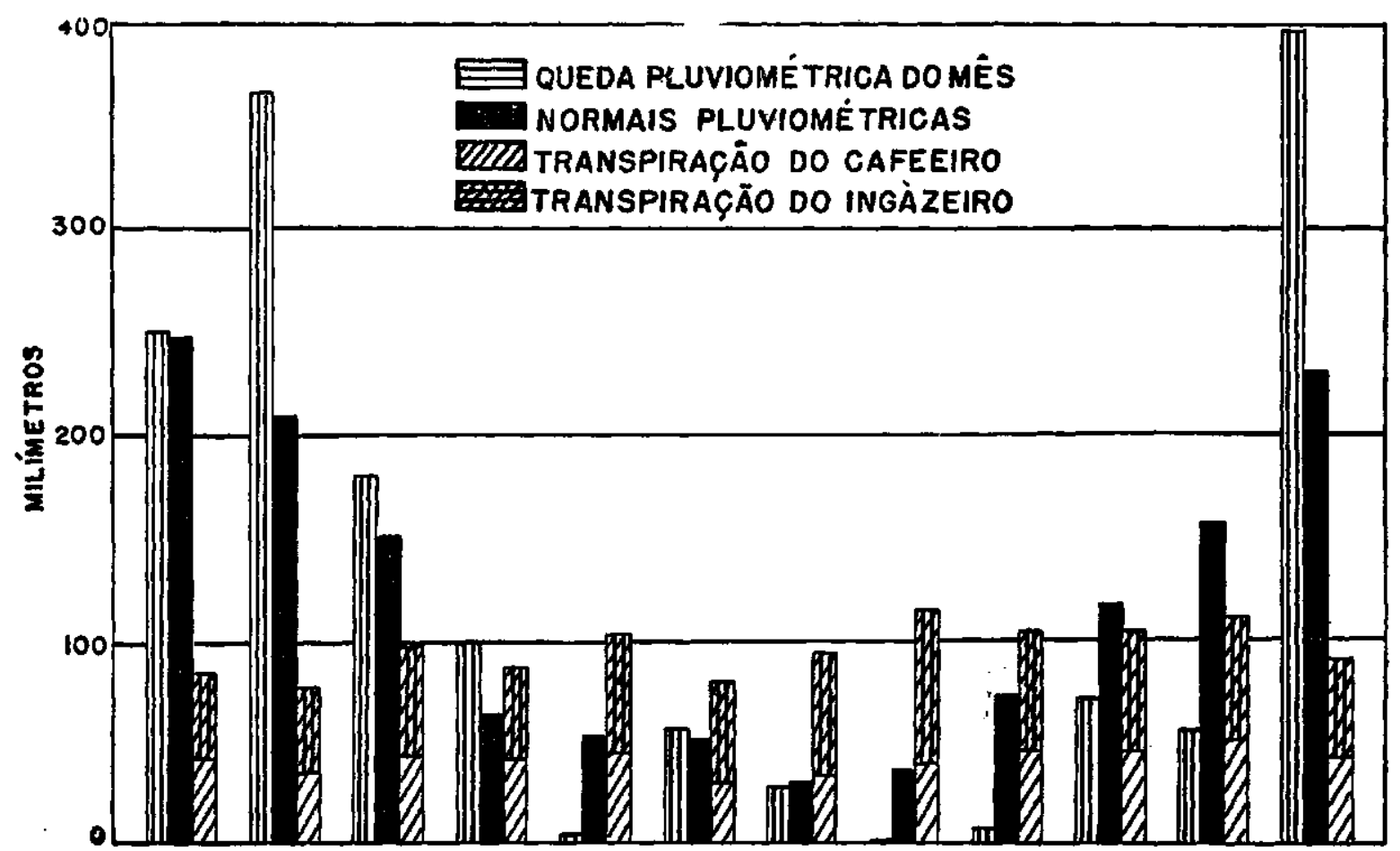

JAN. FEV. MAR. ABR. MAI. JUN. JUL. AGÔ. SET. OUT. NOV. DEZ.

Figura 1.-Quantidade de água transpirada mensalmente pelo cafeeiro sombreado e pelo ingàzeiro, em comparação com a queda pluviométrica, em Campinas, Estado de Sảo Paulo.

Se fôr considerada a soma da transpiração do cafeeiro e a do ingàzeiro, a situação se agrava. Vê-se ainda, no quadro 1 e na figura 1 , que a quantidade de água retirada do solo pela transpiração de ambas as plantas - cafeeiro e ingàzeiro - excede a queda pluviométrica durante os seis meses que vão de abril a setembro.

Como as quedas pluviométricas mensais variam bastante de ano para ano, a situação em um determinado ano pode ser bastante diferente daquela que se apresenta na comparação da transpiração com as médias pluviométricas. Isto pode ser observado na figura 1, comparando-se entre si as colunas correspondentes à transpiração e as que correspondem à queda pluviométrica dos meses em que foi determinada a transpiração.

\section{S U M M A R Y}

The present paper discusses the amount of water lost by the soil through the transpiration of coffee plants and shade trees in shaded coffee plantation.

All methods and techniques employed in the study of transpiration of the shade tree Inga edulis Mart. were exactly the same as those described in a paper recently published (4).

It was determined previously (3) that a shaded coffee plant receiving $55 \%$ of full sunlight transpired $80 \%$ as much as when in $100 \%$ full sunlight. The amount of water transpired by a coffee plant was calculated by taking $80 \%$ of the amount transpired in unshaded plantation (4). 
Comparing the water lost by transpiration of shaded coffee plants and shade trees with the average rainfall in Campinas, São Paulo, Brazil, it is seen that from April to September the amount of water transpired exceeds the average rainfall. This finding seems to agree with our previous conclusion $(1,2,5)$ that water competition between shade trees and coffee plants is the factor that controls the suceess of growing coffee under shade in the State of São Paulo, Brazil.

The highest daily rate of transpiration encountered. for Inga edulis was 36.7 milligrams per square decimeter per minute. The average daily transpiration was found to be 9.90 grams per square decimeter per day.

The total amount of water transpired by an Inga tree was calculated to be 71,140 liters per plant per year. Since the plants submited to the experiment did not suffer a water shortage at any time, the present results show the approximate amount of water lost by the Inga tree and shaded coffee plant under optimal soil-water conditions.

\section{LITERATURA CITADA}

1. Franco, C. M. O problema do sombreamento dos cafèzais em São Paulo. Bol. Superintendência Serviço Café (S. Paulo) 22: 708-717. 1947.

2. Franco, C. M. O problema do sombreamento dos cafèzais em São Paulo. Ceres (Viçosa) 8: 37-51. 1948.

3. Franco, C. M. Pesquisas sôbre a fisiologia do cafeeiro. Sep. Bol. Agric. (S. Paulo) 1947: 1-16. 1949.

4. Franco, C. M. e R. Inforzato. Quantidade de água transpirada pelo cafeeiro cultivado ao sol. Bragantia 10: 247-257, fig. 1-2. 1950.

5. Franco, C. M. A água do solo $\theta$ o sombreamento dos cafèzais em São Paulo. Bol. Superintenđência Serviço Café (S. Paulo), (no prelo). 